\title{
Tearing of Indian mantle lithosphere from high-resolution seismic images and its implications for lithosphere deformation coupling in southern Tibet
}

Jiangtao $\mathrm{Li}^{1}$ and Xiaodong Song ${ }^{1,2}$

${ }^{1}$ University of Illinois at Urbana-Champaign, USA

${ }^{2}$ Wuhan University, China

GSA 2018 


\section{Outline}

- Introduction

- Pn tomography of western china

- Surface-wave tomography of western china

- Model of lithosphere tears: correlations of structure with other observations (seismicity, focal mechanism, surface strain rate, SKS splitting, and surface rifting and geochemistry)

- Conclusions 


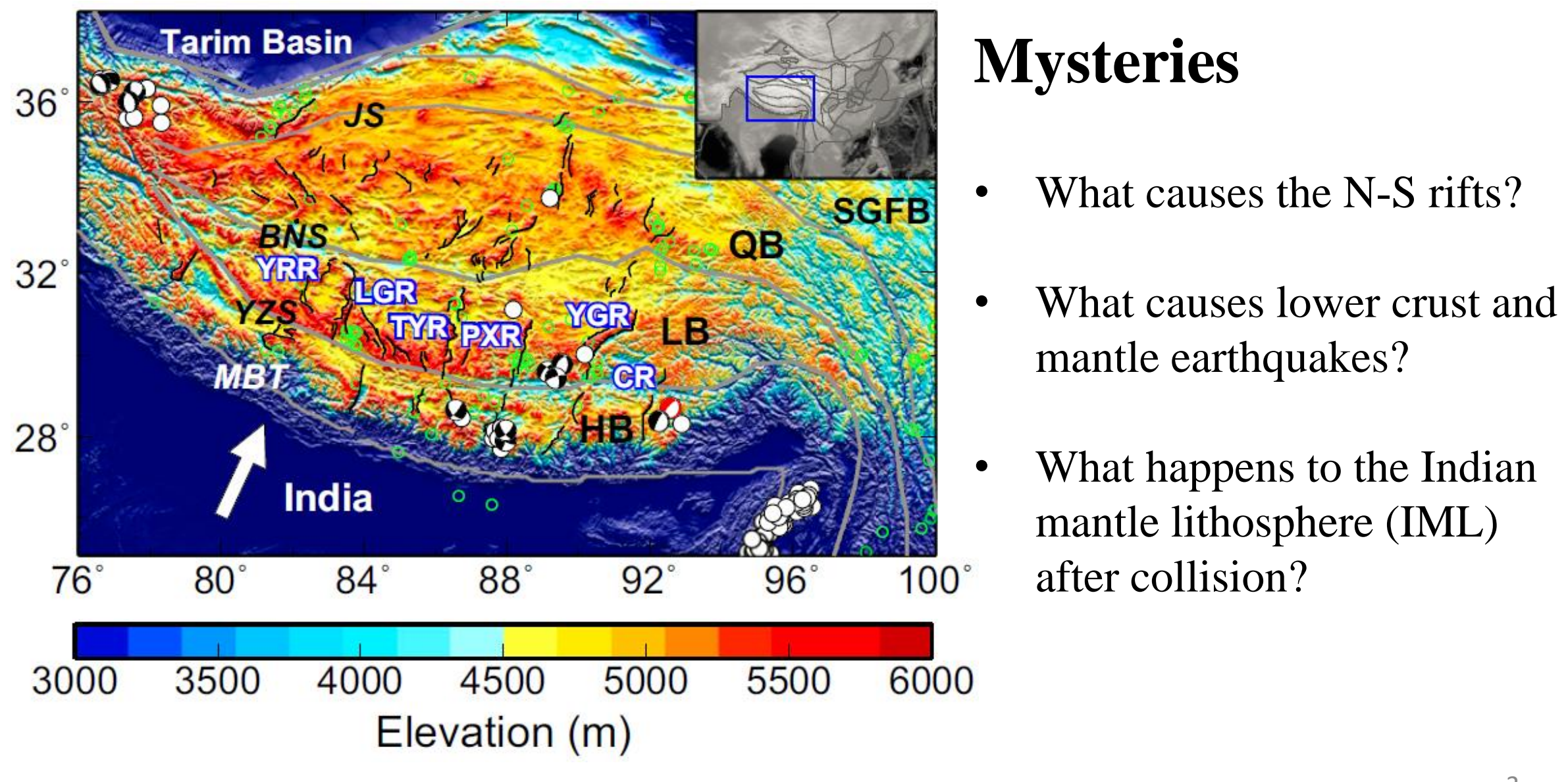




\section{Pn tomography}

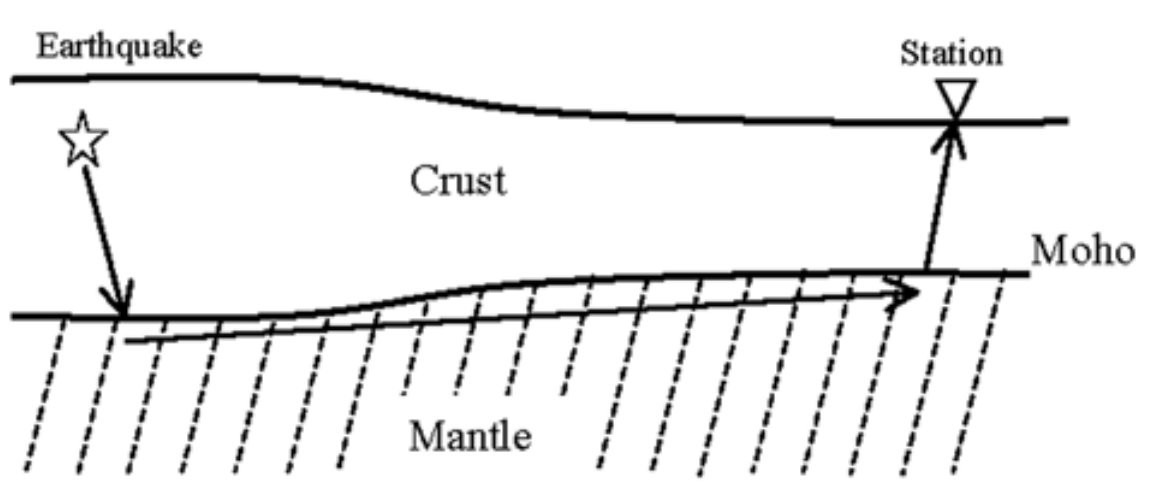

\section{Stations used:}

(1) Liang et al. (2004) \& Liang and Song (2006), bulletin and some hand-picked arrival times (white);

(2) New hand-picked data: Y2 (red), XF (green), YL (magenta), XE (cyan), and some others (blue).

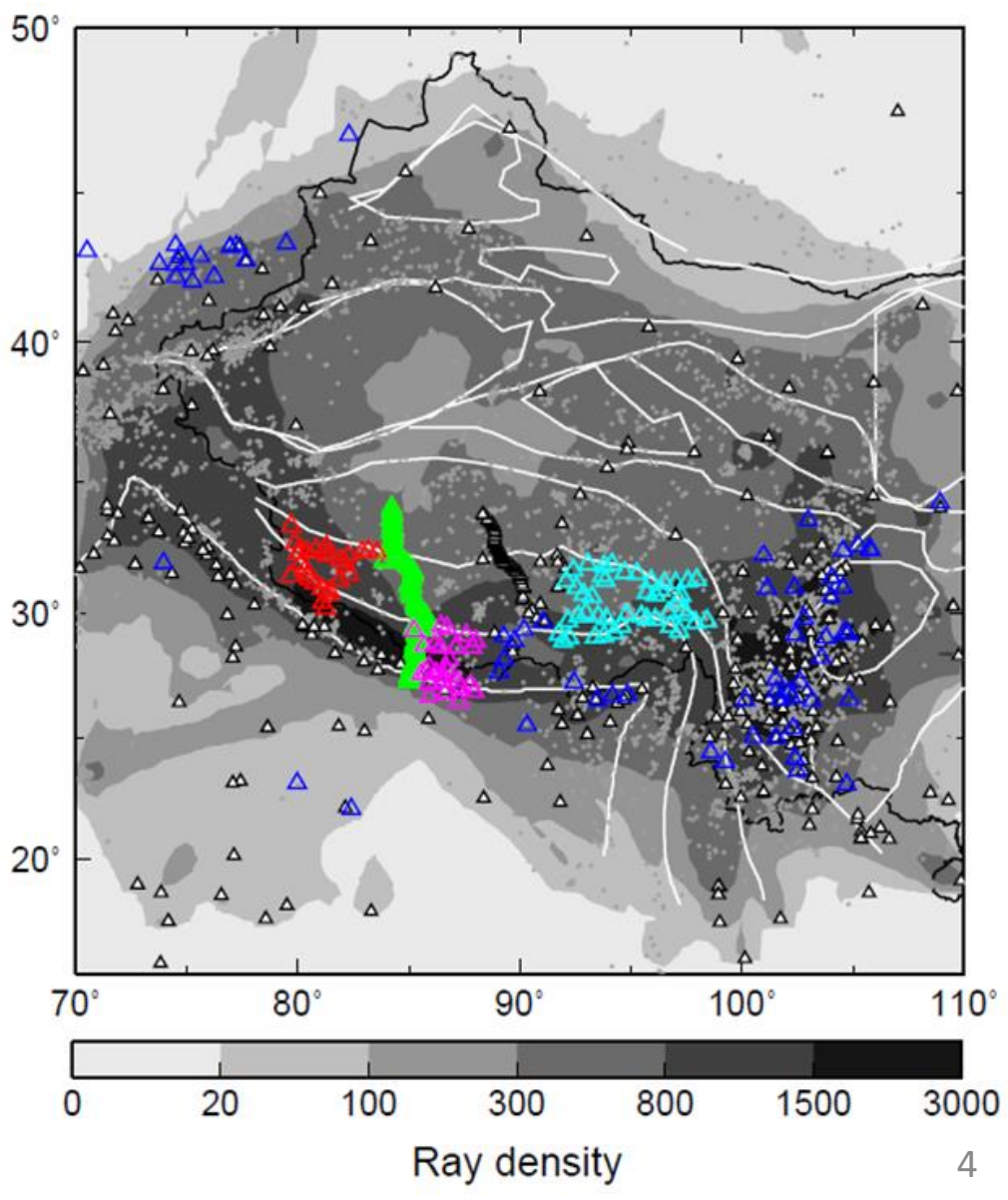




\section{Results: Pn velocity}

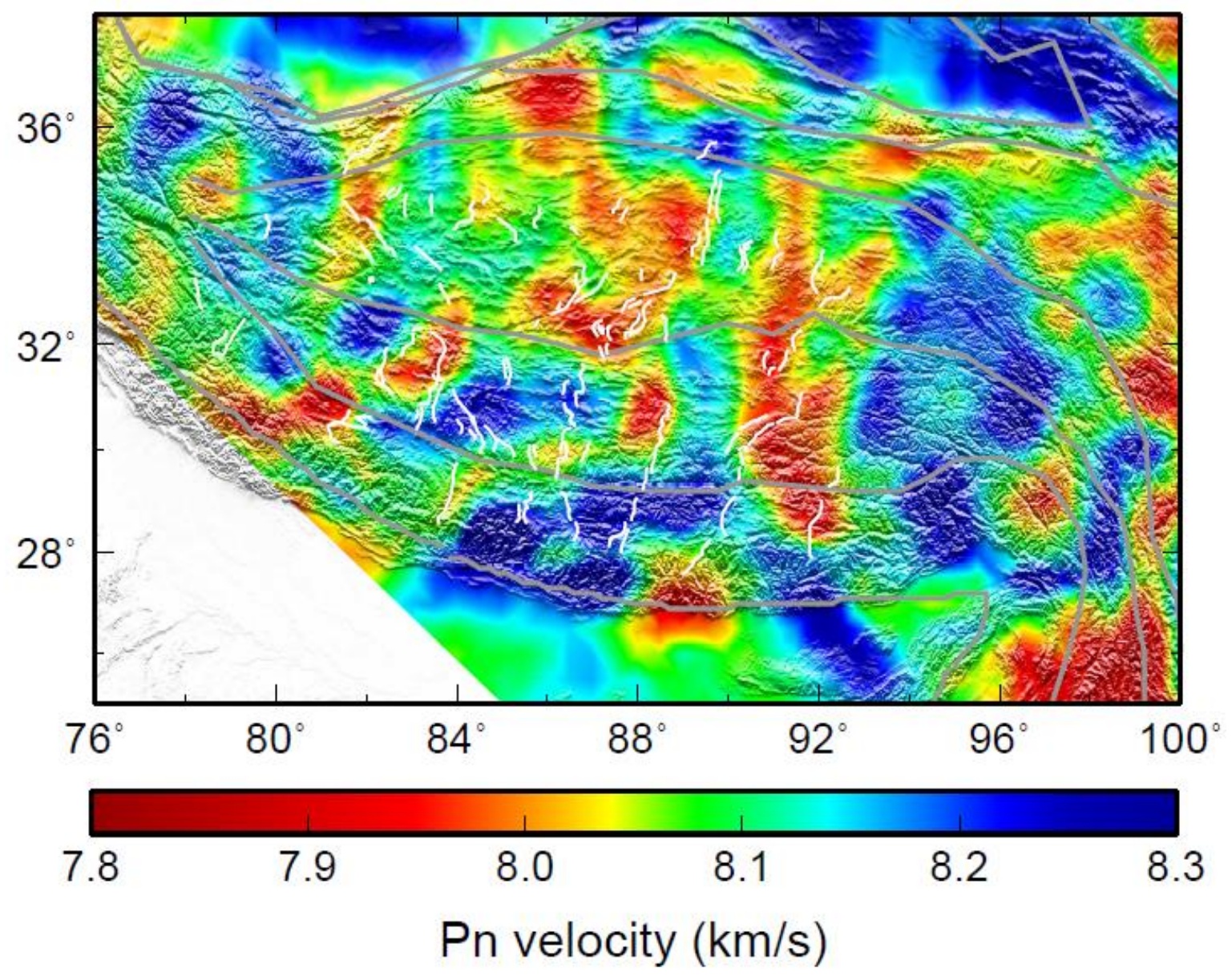




\section{Surface-wave tomography}

\section{Rayleigh waves:}

Group and phase dispersions from ambient noise (10-70 s)

Group dispersions from earthquakes (10-140 s)

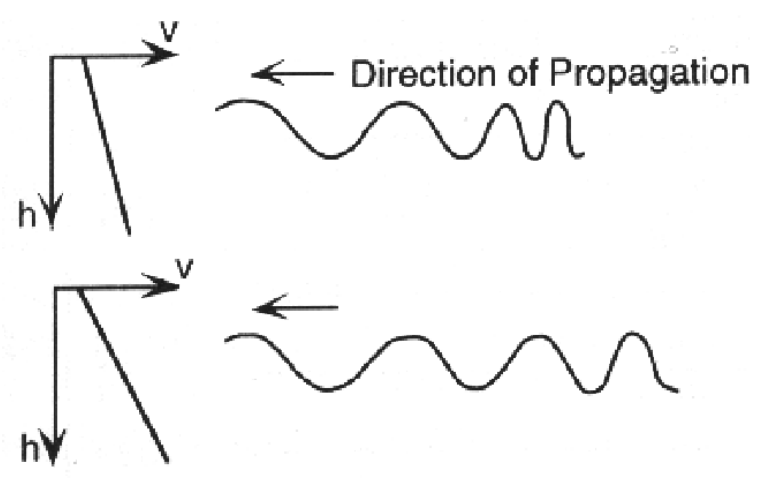

Stronger gradient cause greater dispersion

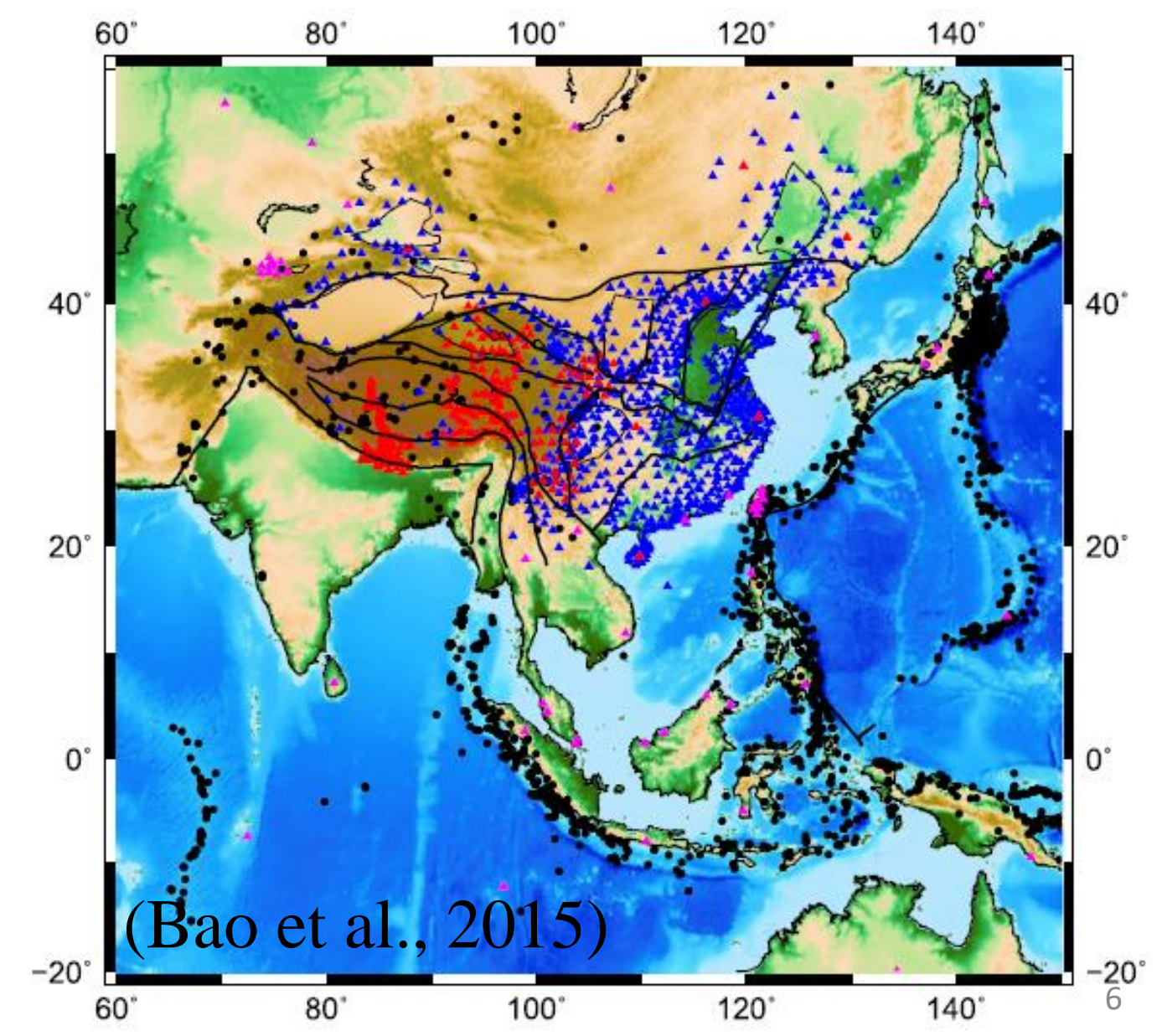




\section{S-velocity model from Bao et al. (2015)}

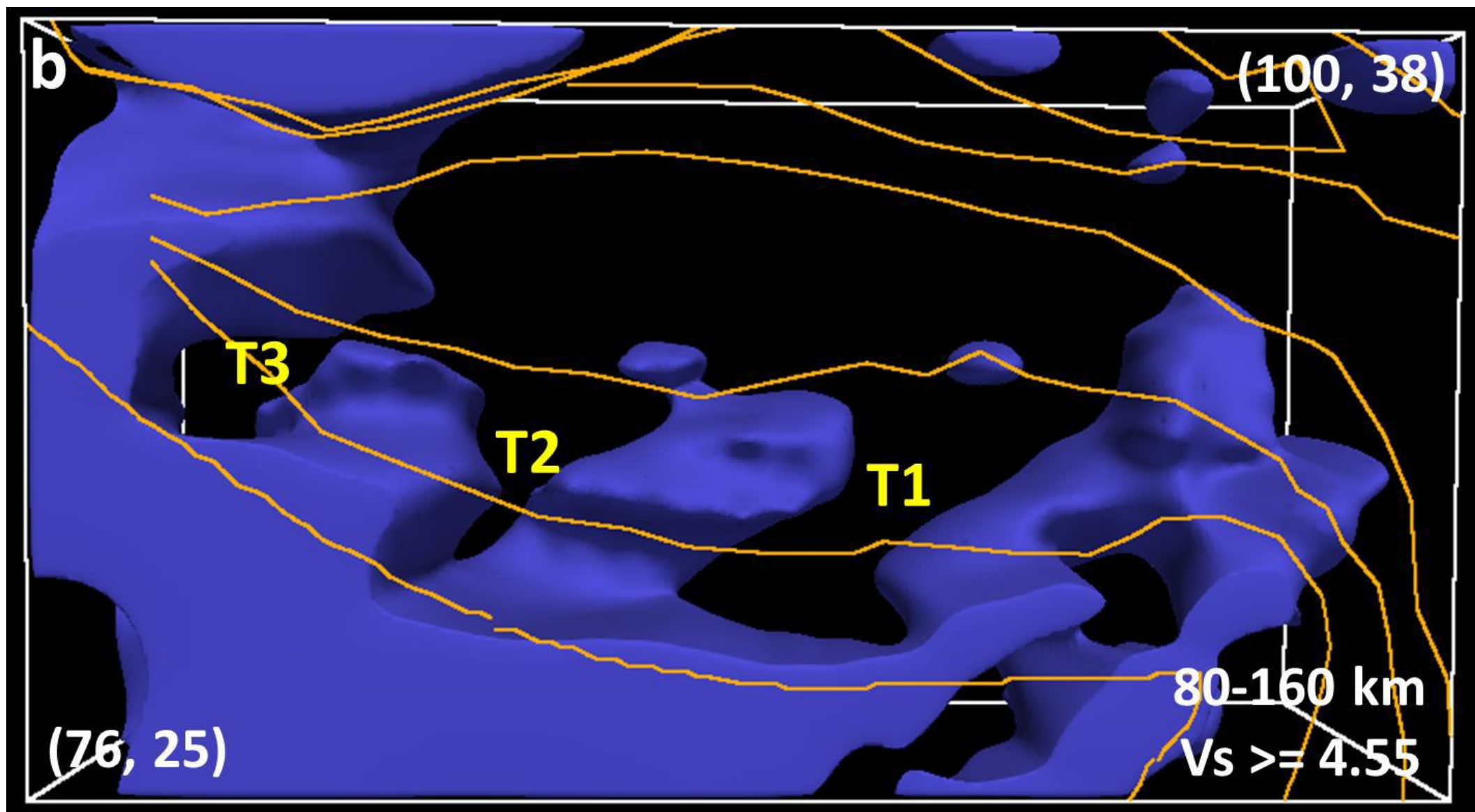




\section{Results: seismicity}
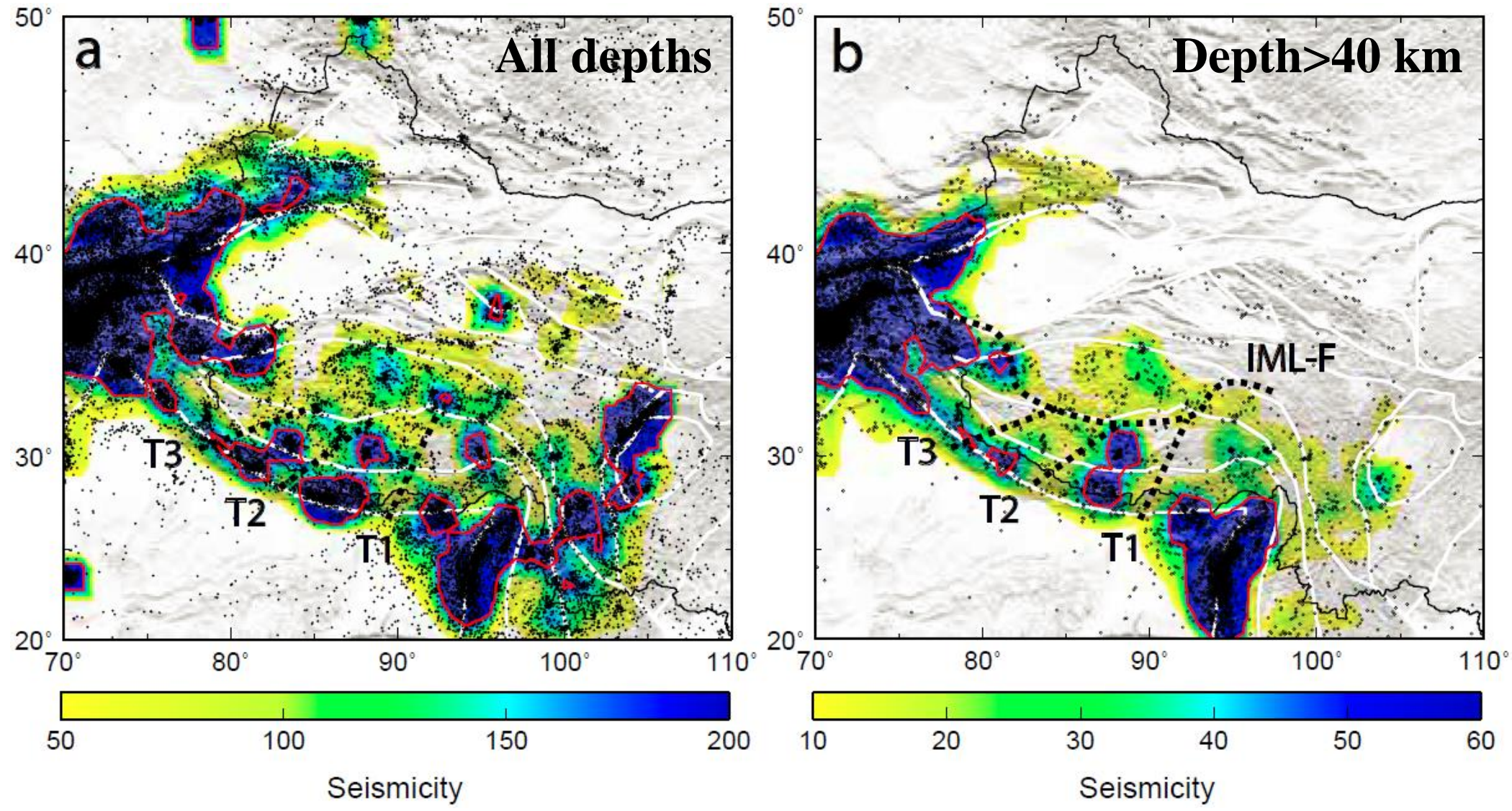

ISC catalog: 1 by $1^{\circ}$ grid, $\#$ of $M>=4$ within $1^{\circ}$, contour of 190 and 50 
$76^{\circ} 78^{\circ} 80^{\circ} 82^{\circ} 84^{\circ} 86^{\circ} 88^{\circ} 90^{\circ} 92^{\circ} 94^{\circ} 96^{\circ} 98^{\circ} 100^{\circ} 102^{\circ}$

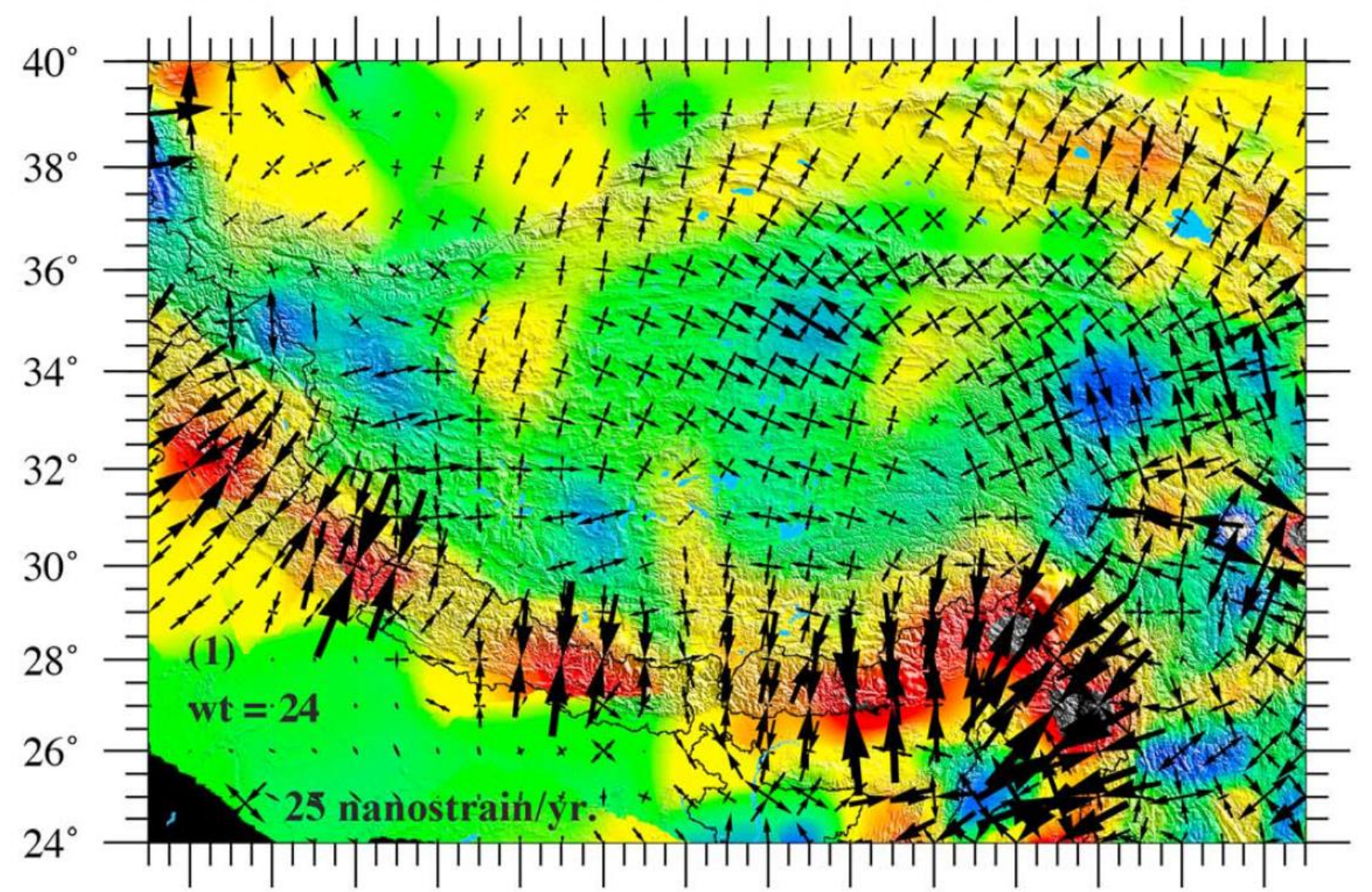

(Ge et al., 2015:

GPS strain rate)

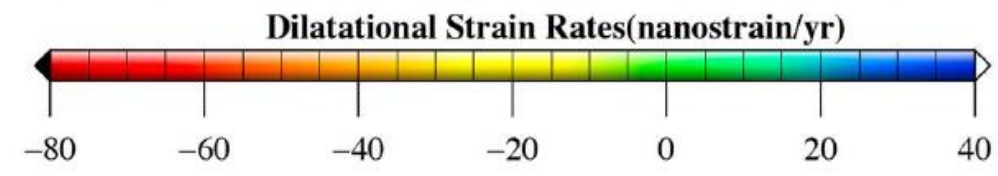




\section{Implications}

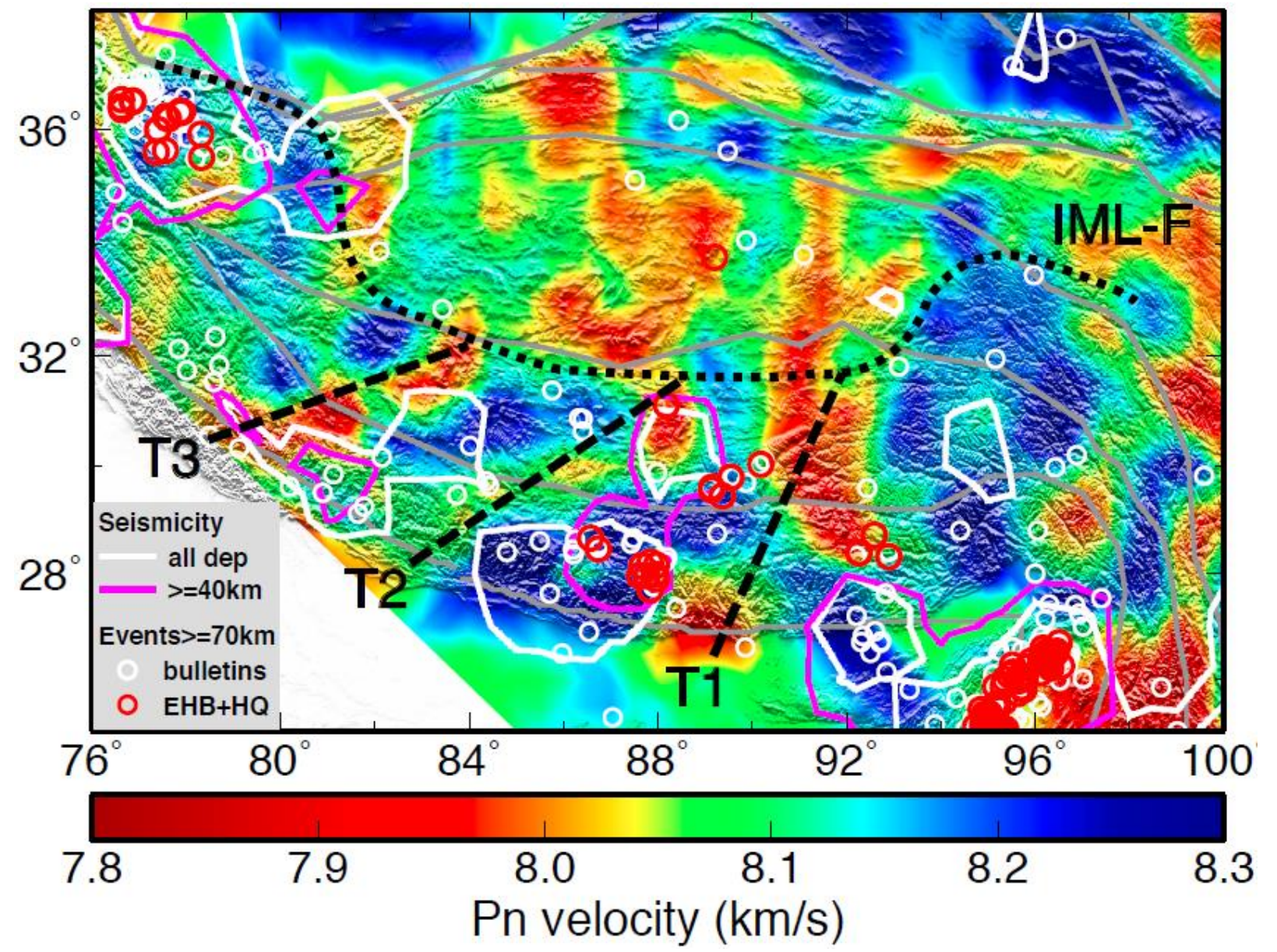




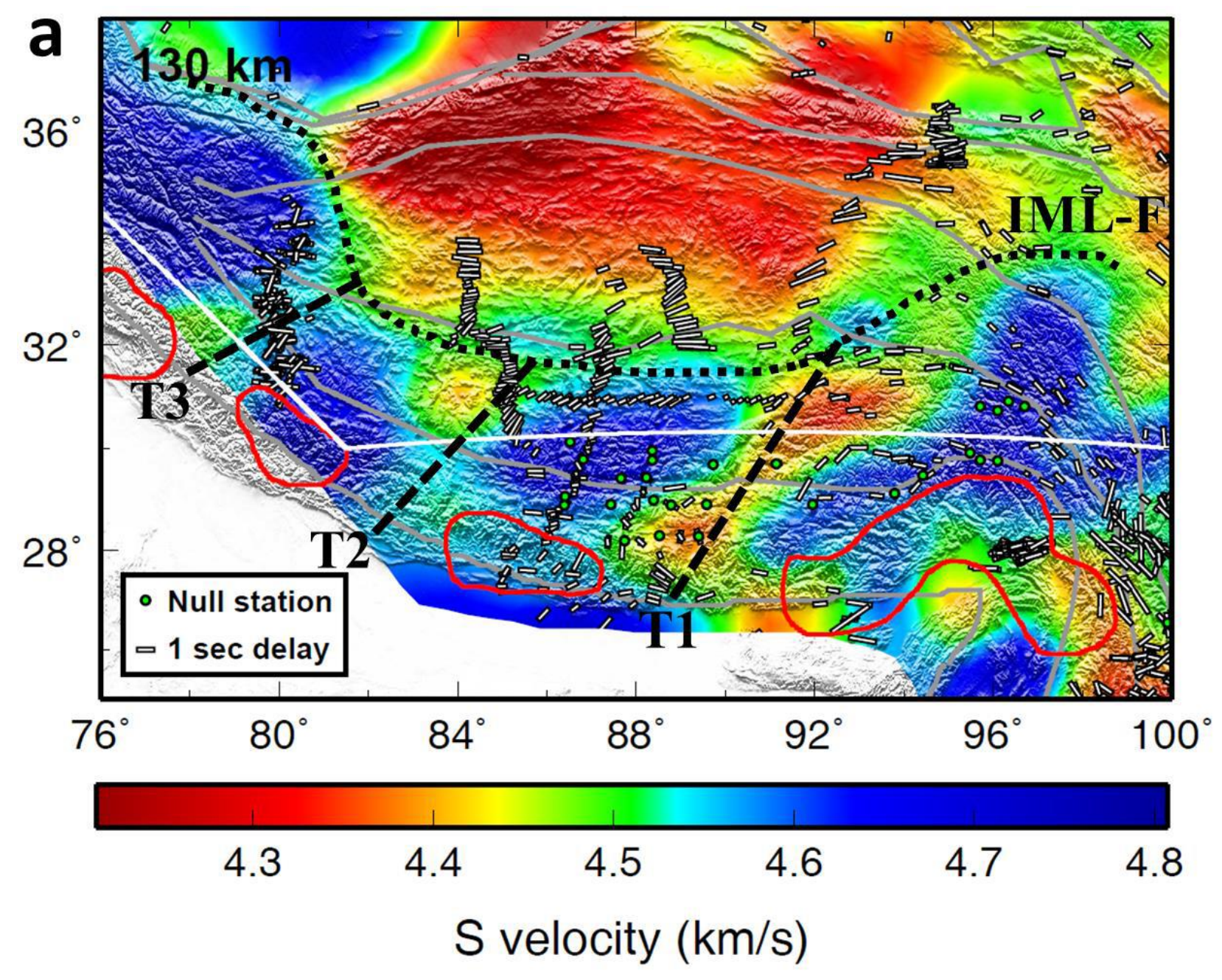




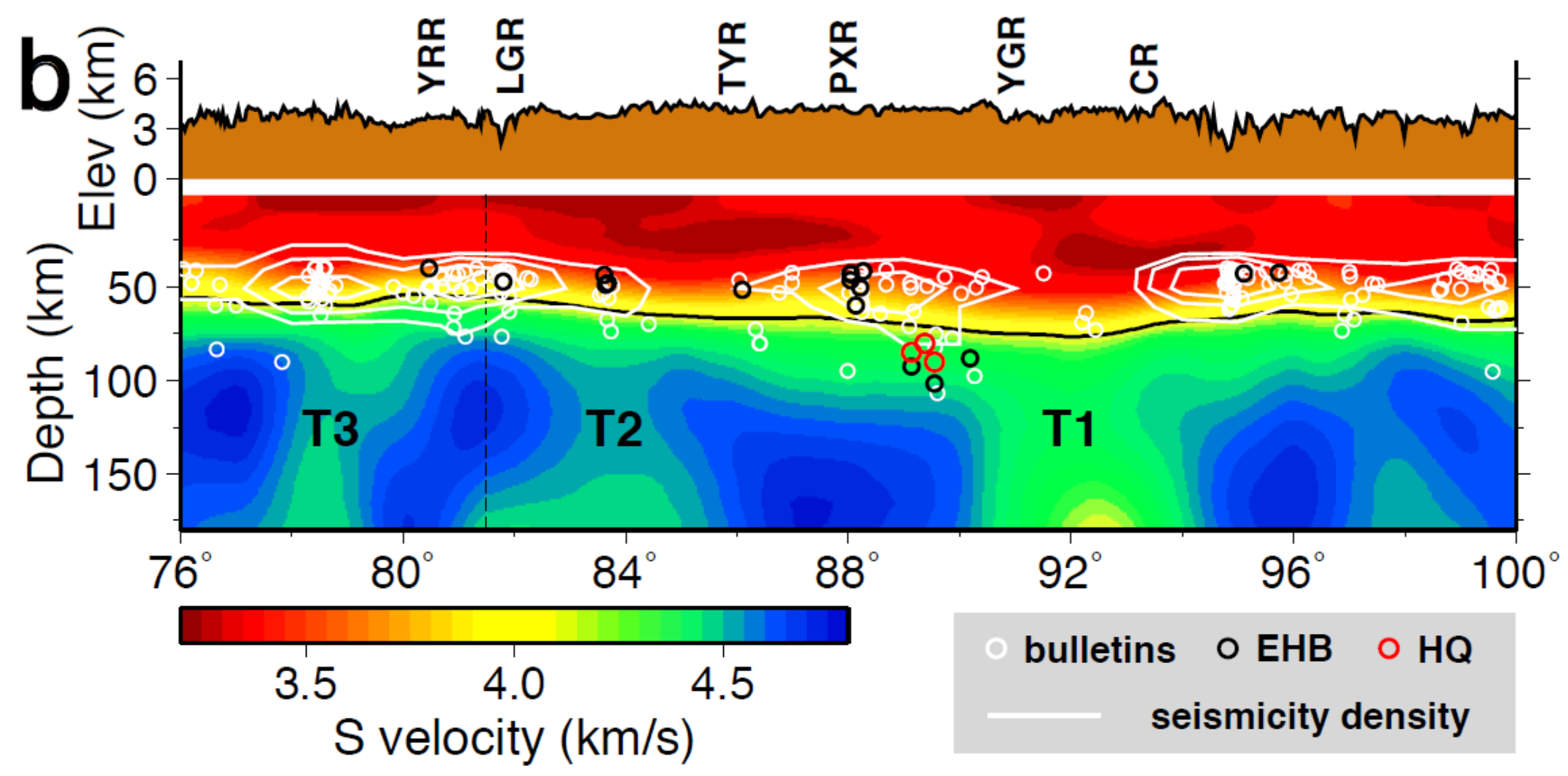




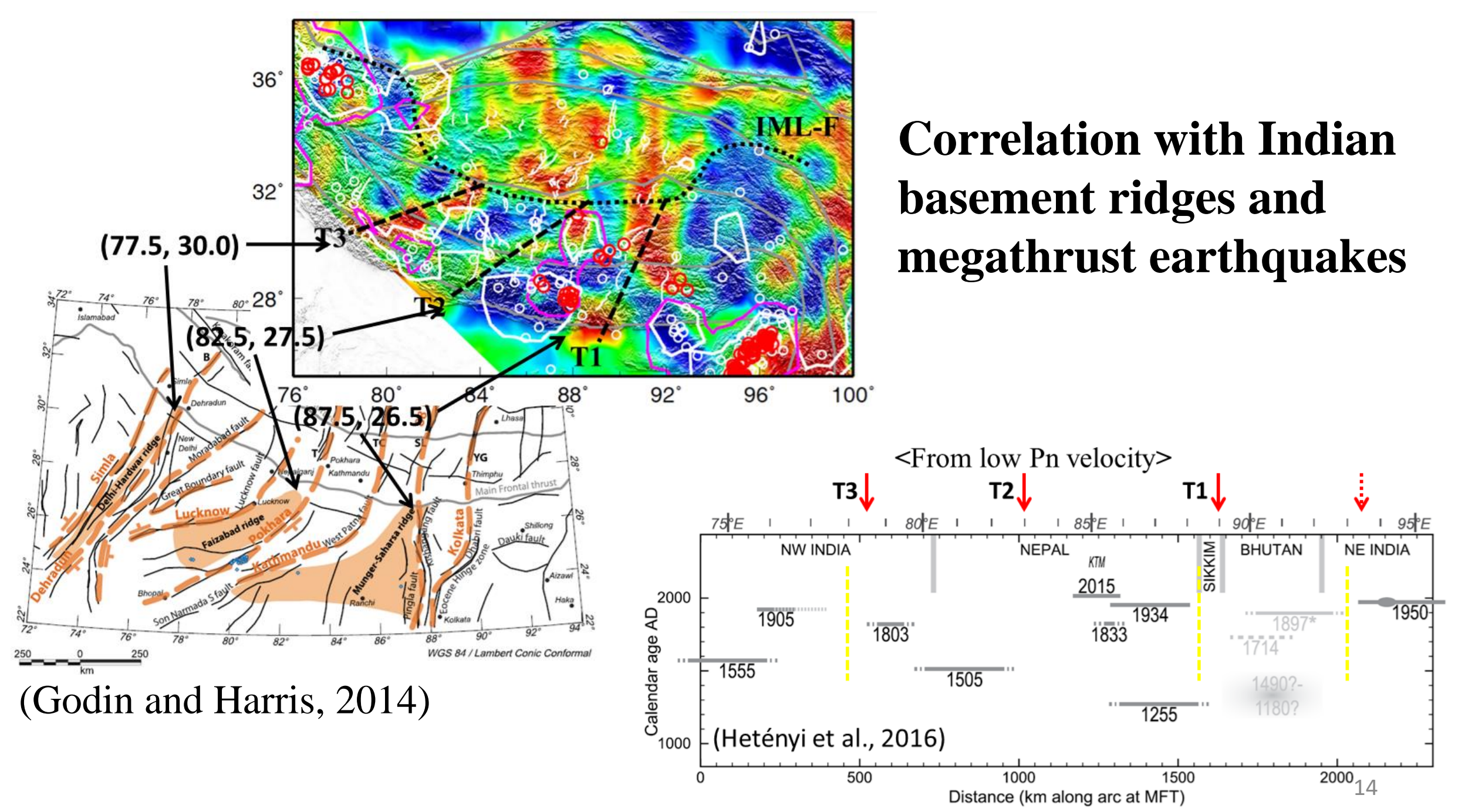




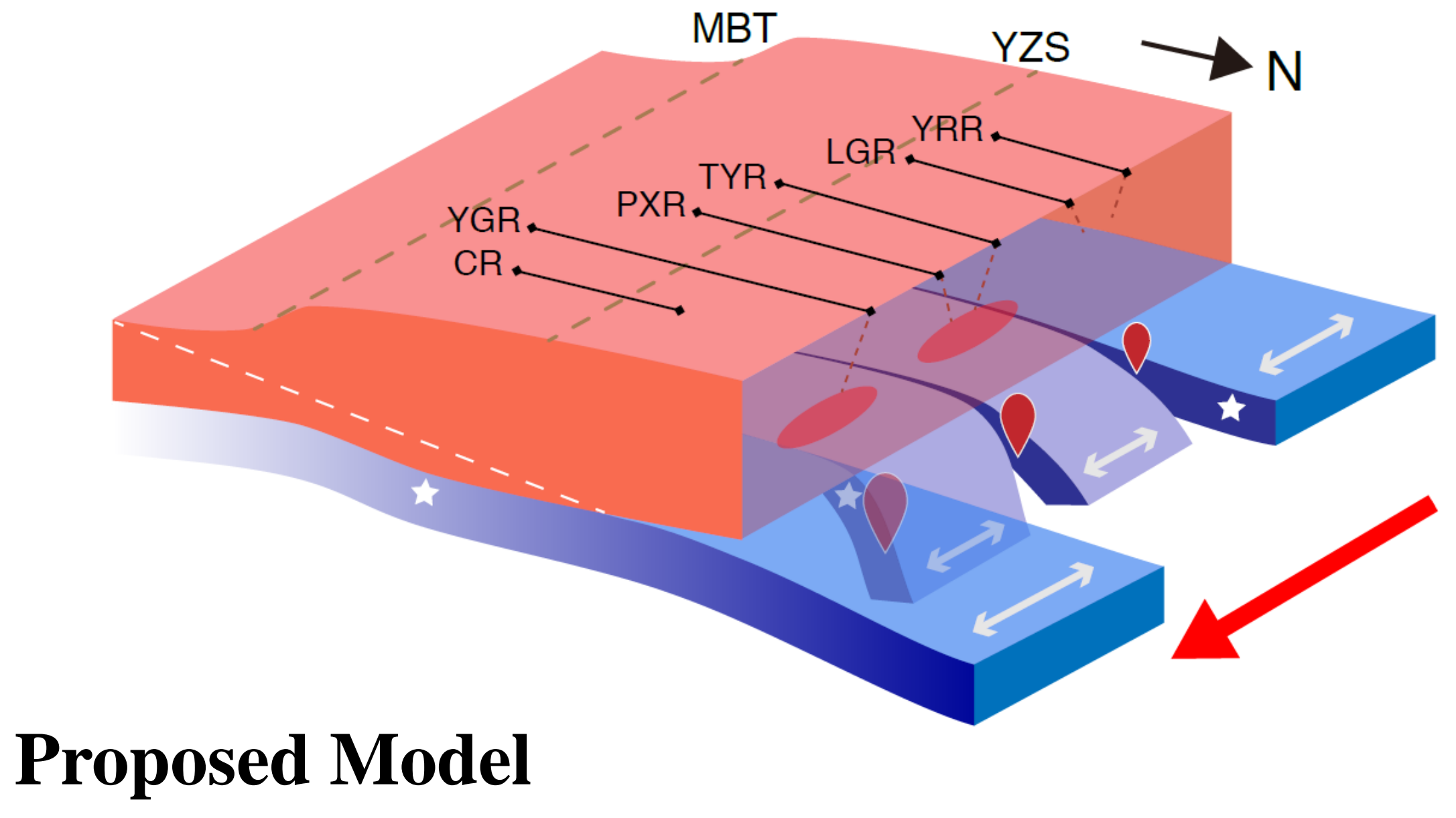




\section{Conclusions}

- High-resolution P and S images suggest that the subducted IML is torn into at least 4 pieces, with different angles and northern limits

- Deep earthquakes in the lower crust and mantle are located almost exclusively in high-velocity part of the Indian lithosphere

- Tearing of the IML provides a unified mechanism for late Miocene and Quaternary rifting, normal faulting, and deep earthquakes in southern and central Tibetan Plateau

- The deformation of the crust and mantle lithosphere is strongly coupled in southern Tibet

- The lateral extent of potential megathrust earthquakes may be limited by the segment boundaries 